\title{
Thermal cycling and isothermal deformation response of polycrystalline NiTi: Simulations vs. experiment
}

\author{
Sivom Manchiraju ${ }^{\mathrm{a}}$, Darrell Gaydosh ${ }^{\mathrm{b}}$, Othmane Benafan ${ }^{\mathrm{c}}$, Ronald Noebe ${ }^{\mathrm{b}}$, \\ Raj Vaidyanathan ${ }^{c}$, Peter M. Anderson ${ }^{\mathrm{a}, *}$ \\ ${ }^{a}$ Materials Science and Engineering, The Ohio State University, Columbus, OH 43210, USA \\ ${ }^{\mathrm{b}}$ NASA Glenn Research Center, 21000 Brookpark Rd., Cleveland, OH 44135, USA \\ ${ }^{c}$ Mechanical, Materials, and Aerospace Engineering, University of Central Florida, 4000 Central Florida Blvd., Orlando, FL 32816, USA
}

Received 1 April 2011; received in revised form 27 April 2011; accepted 28 April 2011

Available online 3 June 2011

\begin{abstract}
A recent microstructure-based FEM model that couples crystal-based plasticity, the B2 $\leftrightarrow$ B19' phase transformation and anisotropic elasticity at the grain scale is calibrated to recent data for polycrystalline NiTi (49.9 at.\% Ni). Inputs include anisotropic elastic properties, texture and differential scanning calorimetry data, as well as a subset of recent isothermal deformation and load-biased thermal cycling data. The model is assessed against additional experimental data. Several experimental trends are captured - in particular, the transformation strain during thermal cycling monotonically increases and reaches a peak with increasing bias stress. This is achieved, in part, by modifying the martensite hardening matrix proposed by Patoor et al. [Patoor E, Eberhardt A, Berveiller M. J Phys IV 1996;6:277]. Some experimental trends are underestimated - in particular, the ratcheting of macrostrain during thermal cycling. This may reflect a model limitation that transformation-plasticity coupling is captured on a coarse (grain) scale but not on a fine (martensitic plate) scale.
\end{abstract}

Published by Elsevier Ltd. on behalf of Acta Materialia Inc.

Keywords: Shape memory alloys; Thermal cycling; Finite element

\section{Introduction}

An important challenge to shape memory alloy (SMA) models is to capture the actuation response [1-3]. A representative situation is shown in Fig. 1a, where the material is subjected to a constant tensile bias stress $\Sigma_{\text {bias }}$ Upon heating, the SMA contracts by a macroscopic transformation strain $E_{\mathrm{T}}$ (feature F7). Other important features are the hysteretic width $\Delta \theta_{\mathrm{H}}$ (feature F6), widths $\Delta \theta_{\mathrm{A}-\mathrm{M}}$ (feature F8) and $\Delta \theta_{\mathrm{M}-\mathrm{A}}$ for the austenite-to-martensite and martensite-to-austenite transformations, respectively, and the open loop strain per thermal cycle, $\Delta E_{\text {cycle }}$ These quantities typically depend on $\Sigma_{\text {bias }}$, composition, processing history and microstructural features such as single/polycrystalline

\footnotetext{
* Corresponding author. Tel.: +1 6142921537.

E-mail address: anderson.1@osu.edu (P.M. Anderson).
}

orientation/texture, precipitate morphology, dislocation substructure and internal stress (e.g. [4]).

SMA models can be characterized by their microstructural detail and phenomenological nature. For example, some track the volume fractions of stress-induced vs. thermally induced martensite via state variables $[5,6]$ or adopt a functional dependence of transformation strain on the total martensite volume fraction and stress [7]. Others include a phenomenological description of transformation-induced plasticity [8-11]. Variant-level models (e.g. [12-20]) track the volume fraction of individual martensite variants, thereby capturing effects of texture and crystal orientation. One version includes a recursive algorithm method that adjusts interactions between competing tetradomains in order to reproduce neutron diffraction data [21]. The method captures the evolution of martensite volume fraction and local stress for various $\langle h k l\rangle$ sets of domains [22]. 

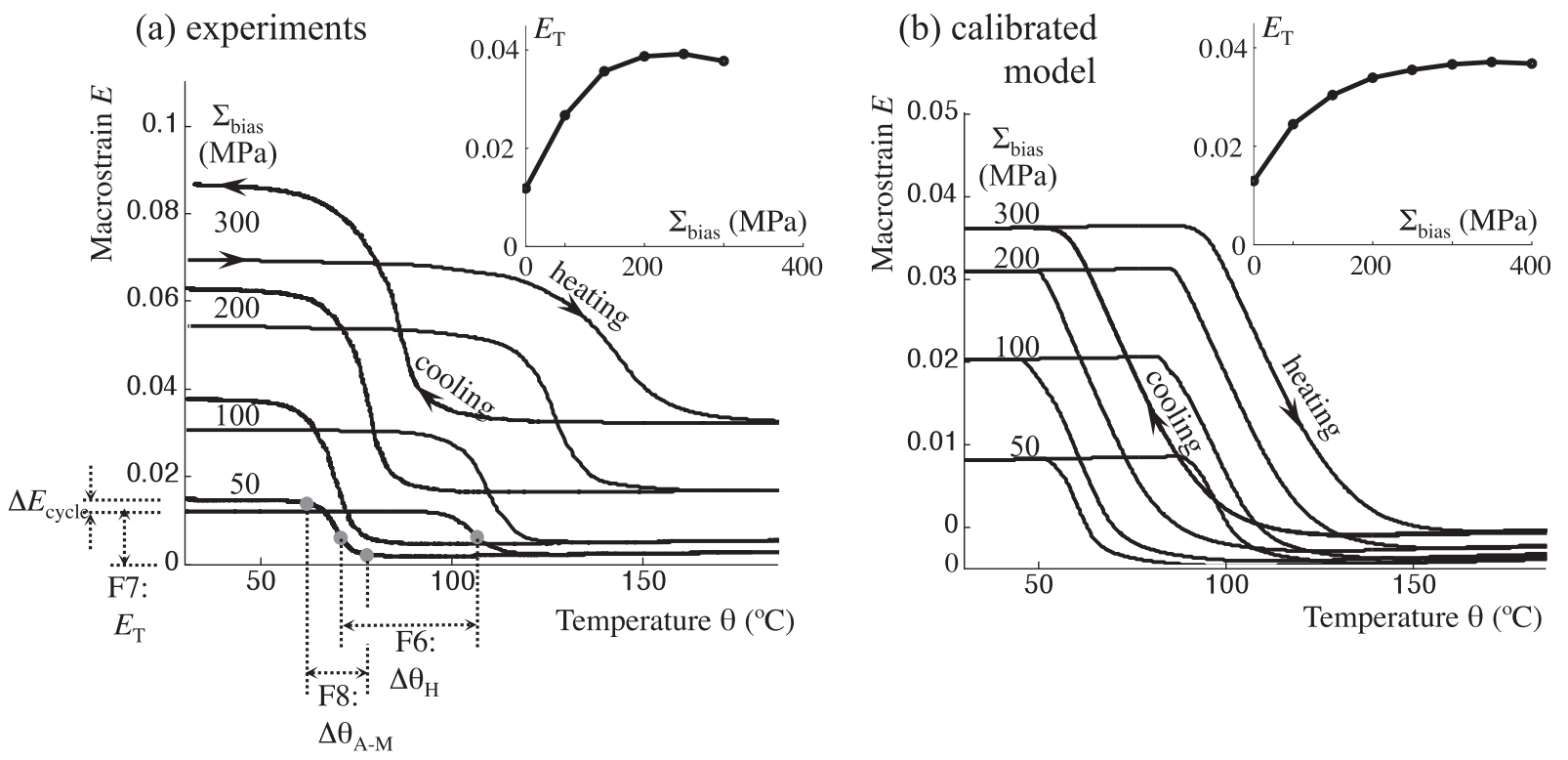

Fig. 1. Axial macrostrain $E$ vs. temperature $\theta$ during thermal cycling with an axial bias stress $\Sigma_{\text {bias: }}$ (a) experimental data for the 49.9 at. $\%$ Ni-Ti alloy and (b) calibrated model results. The inserts show the transformation strain $E_{\mathrm{T}}$ vs. $\Sigma_{\text {bias, }}$, where $E_{\mathrm{T}}$ is defined by feature $\mathbf{F} 7$ in (a). The calibrated model parameters are presented in Table 1.

A particular challenge to simulate actuator performance is to capture the initial, gradual increase in $E_{\mathrm{T}}$ with $\Sigma_{\text {bias }}$, the attainment of a peak $E_{\mathrm{T}}$ at moderate $\Sigma_{\text {bias }}$ and the decrease in $E_{\mathrm{T}}$ at larger $\Sigma_{\text {bias }}$ (Fig. 1a, inset). The gradual increase in $E_{\mathrm{T}}$ tests model assumptions about martensite interactions. These can be formulated between individual twinned habit plane variants (hpv) [14-17,23], hpv groups [24] and lattice correspondence variants (lcv) [25], or groups thereof [21,22]. An implementation of the first type by Patoor et al. [23] has been used (e.g. [15-17]), but the predicted $E_{\mathrm{T}}$ increases too abruptly with $\Sigma_{\text {bias }}[25]$.

The peak in $E_{\mathrm{T}}$ with $\Sigma_{\text {bias }}$ tests model assumptions concerning plasticity. Most do not incorporate it at all [12-16], including the aforementioned recursive model [21,22]. Some recent efforts have included martensite plasticity, either in J2-based [18,26] or crystal-based [17] forms. However, austenite rather than martensite plasticity has been observed in recent transmission electron microscope studies of pseudoelastically deformed, solutionized 50.7 at.\% $\mathrm{Ni}-\mathrm{Ti}$ single crystal pillars [27] and cold-worked 50.8 at.\% Ni-Ti wires [28], as well as thermally cycled, singlecrystal 50.4 at.\% Ni-Ti [29]. In particular, a detailed analysis reveals that transformation-induced dislocations have Burgers vectors and slip planes with rationale directions in the austenite basis rather than the martensite basis [27]. These observations follow earlier work documenting the formation of planar dislocation arrays during loadbiased thermal cycling of 50.1 and 50.4 at.\% Ni-Ti [30]. Plastic deformation has also been proposed to explain progressive widening of the $\left\{\begin{array}{lll}1 & 1 & 0\end{array}\right\} \mathrm{B} 2$ peak during load-biased thermal cycling [31].

Consequently, a principal contribution of this paper is to determine whether a crystal-based modeling approach that incorporates austenite plasticity can capture the key thermal cycling features shown in Fig. 1a as well as other data. This recent finite element (FE) approach [32] couples a crystal-based description of the evolution of martensite hpv by Thamburaja and Anand [13] with a crystal-based description of austenite plasticity based on Peirce et al. [33]. Thus, it is able to assess the Patoor et al. [23] formalism for hpv-hpv interaction as well as hpv-crystal plasticity interaction. Other unique features are inclusion of rigorous formalisms for anisotropic elastic deformation in the austenite and martensite phases, as well as predictions of the orientation of individual Bain strain variants of martensite. Recently reported elastic constants for monoclinic martensite [34] are included, as well as the appropriate invariant-plane condition between austenite and martensite - a feature not satisfied in a recent self-consistent approach to incorporate anisotropic elasticity [35].

The structure of the manuscript is as follows: Section 2 describes experimental data for the polycrystalline 49.9 at. $\% \mathrm{Ni}-\mathrm{Ti}$ material system, performed in support of the modeling activity. Section 3 describes the FE model. Section 4 presents the process for calibrating the model parameters to a subset of experimental data, and Section 5 assesses predictions of the calibrated model to additional data. Section 6 provides an overall assessment of model capabilities and conclusions.

\section{Experimental characterization}

\subsection{Material system and history}

The binary 49.9 at.\% (55 wt.\%) Ni-Ti alloy used in this study is described elsewhere [2]. It was produced by Special 
Metals, New Hartford, NY and supplied as $10 \mathrm{~mm}$ diameter rods in a hot-rolled/hot-drawn and hot-straightened condition. The specific thermo-mechanical processing history is proprietary. The alloy is single phase, with a dynamically recrystallized and equiaxed grain structure with $\sim 40 \mu \mathrm{m}$ average grain size.

All experimental measurements on as-machined specimens were preceded by two no-load thermal cycles from 30 to $200{ }^{\circ} \mathrm{C}$ at $20^{\circ} \mathrm{C} \mathrm{min}^{-1}$. The nominal purpose is to reduce internal stress generated by material processing and machining.

\subsection{Texture analysis}

The as-received alloy had a very weak recrystallization texture. Fig. 2a shows the pole figures in the austenite phase at $200^{\circ} \mathrm{C}$. They were obtained using the high-pressure preferred orientation (HIPPO) neutron diffractometer at Los Alamos National Laboratory (LANL) [36].

\subsection{Differential scanning calorimetry}

Differential scanning calorimetry (DSC) tests were performed to measure the heat of transformation, $Q_{\mathrm{DSC}}$, the martensite start and finish temperatures, $\theta_{\mathrm{MS}}$ and $\theta_{\mathrm{MF}}$, and the austenite start and finish temperatures, $\theta_{\mathrm{AS}}$ and $\theta_{\mathrm{AF}}[2]$. Key results were determined from a $n=7$ DSC sampling size and are summarized in Section 4.2.

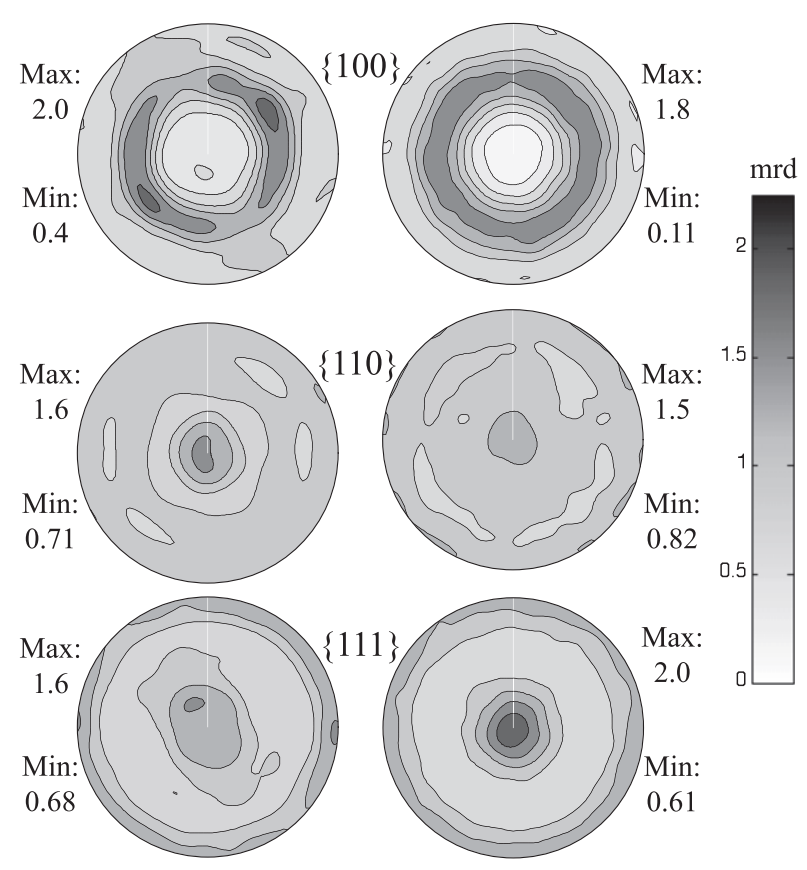

(a) Experiments

(b) simulations

Fig. 2. Pole figures for as-received austenitic polycrystalline 49.9 at. $\% \mathrm{Ni}-$ $\mathrm{Ti}$ at $200{ }^{\circ} \mathrm{C}$ from (a) neutron diffraction data using HIPPO and (b) simulations based on SMARTS diffraction data [2] for the same material at $200{ }^{\circ} \mathrm{C}$, using POPLA software [46] and assuming axisymmetry. A stronger $\left(\begin{array}{lll}1 & 1 & 1\end{array}\right)$ and weaker $\left(\begin{array}{lll}1 & 0 & 0\end{array}\right)$ texture are apparent.

\subsection{Pseudoelastic and plastic strains above $\theta_{A F}$}

Fig. 3a shows the uniaxial tension stress-strain response at $\theta_{0}=130{ }^{\circ} \mathrm{C}$ for maximum imposed axial strains $E_{\max }=0.02$ and 0.04 , and also at $215^{\circ} \mathrm{C}$ for $E_{\max }=0.04$. Stress-induced martensite forms during deformation above $\theta_{\mathrm{AF}}$ and some is retained upon unloading. A small axial strain rate of $10^{-4} \mathrm{~s}^{-1}$ was used to help ensure isothermal conditions. After $E_{\max }$ was attained, the sample was unloaded isothermally and then heated to $600{ }^{\circ} \mathrm{C}$ under no load. During heating, the macrostrain $E$ decreased due to recovery (transformation) of stabilized martensite to austenite. It was then cooled back to $\theta_{0}$ Recovery was confirmed by noting that the macrostrain-temperature $(E-\theta)$ response during initial cooling is consistent with the thermal expansion coefficient of austenite [37]. The strain $E_{\text {post-heat }}$ (feature F13, Fig. 3a) at $\theta_{0}$ is expected to be due primarily to plastic deformation.

This NiTi alloy does not exhibit a strong, "flag-like" pseudoelastic response, as typically observed above $\theta_{\mathrm{AF}}$ in Ni-rich NiTi alloys [12-15,28,29,38-42] or cold-worked and annealed Ti-rich NiTi alloys [43]. The more idealized pseudoelastic response, with clear loading and unloading plateaus and large recoverable strains, is obtained in microstructures that suppress plastic deformation [44] yet permit stress-induced transformation. In practice, this is achieved through grain refinement $[28,42]$, cold work with partial recovery [43] or precipitation strengthening of Ni-rich NiTi alloys through suitable heat treatment [38-41]. Such strategies were not pursued here since the goal was to study the simultaneous effects of plasticity and transformation. Indeed, the features in Fig. 3a (and Fig. 1a) show evidence of both plasticity and pseudoelastic transformation, making it a suitable system to test the polycrystalline simulations.

\subsection{Load-biased thermal cycling}

Fig. 1a shows the $E-\theta$ response of the NiTi alloy at different values of uniaxial bias stress $\left(\Sigma_{\text {bias }}\right)$. The stress level was achieved by imposing a $10^{-4} \mathrm{~s}^{-1}$ axial strain rate at $\theta_{\min }=30^{\circ} \mathrm{C}$, where martensite is stable, until the desired stress was reached at constant temperature. The controller was switched into load control and the stress was held constant. This was followed by thermal cycling up to $\theta_{\max }=200{ }^{\circ} \mathrm{C}$ and back to $\theta_{\min }=30^{\circ} \mathrm{C}$ at constant $\Sigma_{\text {bias }}$ The second thermal cycle responses are shown in Fig. 1a, as well as the transformation strain $E_{\mathrm{T}}$ vs. $\Sigma_{\text {bias }}$ (inset).

\subsection{In situ neutron diffraction}

Neutron diffraction spectra were obtained during stressbiased thermal cycling, using the protocol in Section 2.5. These measurements were obtained in "time-of-flight" mode using the Spectrometer for MAterials Research at Temperature and Stress (SMARTS) facility at LANL. 

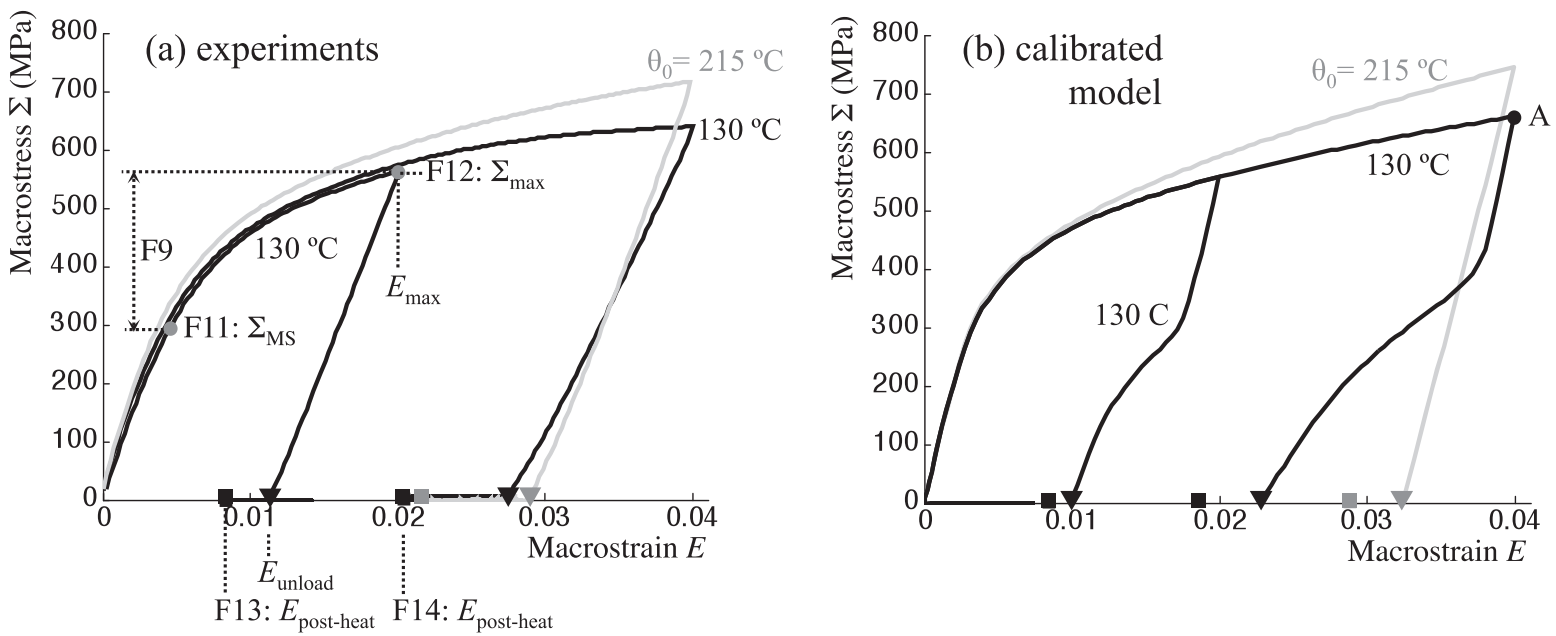

Fig. 3. Axial macrostress $\Sigma$ vs. macrostrain $E$ at $\theta_{0}=130$ vs. $215^{\circ} \mathrm{C}$ showing (a) experimental data for the 49.9 at. $\%$ Ni-Ti alloy and (b) calibrated model results. $E_{\text {unload }}$ and $E_{\text {post-heat }}$ are the respective macrostrains after unloading and after a subsequent $600{ }^{\circ} \mathrm{C}$ heat treatment of the unloaded sample. The calibrated model parameters are presented in Table 1.

Two detector banks furnished the diffracted intensity vs. $d$ spacing from two groups of crystallographic planes: those parallel and those perpendicular to the loading axis. The data give the evolution of martensite and austenite (volume fraction and orientation) during thermal cycling. Additional details are provided in Ref. [2] and the references therein.

\section{Polycrystalline simulations and constitutive relation}

\subsection{Polycrystalline simulations}

A brief description of the finite element representation of the polycrystal and boundary conditions is provided, with emphasis on texture specification and new model extensions as noted in Section 1. Additional details are provided in Ref. [32].

\subsubsection{Discretization at the grain scale and texture specification}

The polycrystal was modeled by a $7 \times 7 \times 7$ cube assembly of 8-node three-dimensional brick elements (C3D8 for isothermal analyses and C3D8T for thermo-mechanical analyses) using the commercial FE software ABAQUS [45]. Each element represented a grain with an assigned crystal orientation of the austenite (B2) phase. These orientations were based on a simulated texture for the asreceived NiTi (Fig. 2b), obtained by processing SMARTS data [2] with the texture analysis software POPLA [46], assuming an axisymmetric texture. This assumption and the stronger ( $\left.\begin{array}{lll}1 & 1 & 1\end{array}\right)$ and relatively weaker $\left(\begin{array}{llll}1 & 0 & 0\end{array}\right)$ textures present in the SMARTS data compare favorably with subsequent HIPPO data shown in Fig. 2a (Section 2.2). The number of grains, $N_{\text {grain }}=343$, in the simulations is sufficient since the macroscopic response does not change significantly for $N_{\text {grain }}>343$.

\subsubsection{Predeformation $E_{p(\text { pre })}$ in the austenitic state}

Some internal stress is expected in the samples prior to testing, even though the material was hot-worked and two no-load or stress-free thermal cycles were imposed before testing. The simulations introduced internal stress via predeformation in the austenitic state. This was achieved by heating to $300{ }^{\circ} \mathrm{C}$, at which temperature austenite is stable, imposing a macroscopic plastic prestrain $E_{\mathrm{p}(\text { pre) }}$ at $10^{-4} \mathrm{~s}^{-1}$, unloading, then cooling to the desired test temperature $\theta_{0} E_{\mathrm{p}(\mathrm{pre})}$ was varied to match the experimental data (Section 4.3).

\subsubsection{Isothermal deformation testing and post-heating}

The polycrystal was strained to $E_{\max }$ at some constant temperature $\theta_{0}>\theta_{\mathrm{AF}}$ and then unloaded. This was achieved via prescribed normal displacement rates and zero shear tractions on the top and bottom surfaces, equivalent to an axial strain rate of $\pm 10^{-4} \mathrm{~s}^{-1}$. The transverse faces were traction free. The macrostrain $E_{\text {unload }}$ after unloading was partitioned into plastic and transformation contributions by integration of the local plastic and transformation strains over the polycrystal. The simulations assumed spatially uniform, isothermal conditions. This is considered reasonable since the small imposed strain rate minimizes local heating and heat transfer rates associated with the austenite-martensite phase transformation. Fig. 3b shows results using the calibrated model.

\subsubsection{Stress-biased thermal cycling}

The polycrystal was heated to the maximum cycling temperature $\theta_{\max }=190{ }^{\circ} \mathrm{C}$, then the bias stress $\Sigma_{\text {bias }}$ was imposed using an axial strain rate of $10^{-4} \mathrm{~s}^{-1}$. The sample was then cycled between $\theta_{\min }=30^{\circ} \mathrm{C}$ and $\theta_{\max }$ at $\pm 0.08{ }^{\circ} \mathrm{C} \mathrm{s}^{-1}$. The simulations assumed a spatially uniform temperature, which is reasonable, given the small heating/ cooling rate. The simulations began the load application 
and cycling at $\theta_{\max }$, compared to $\theta_{\min }$ for the experiments. However, previous experiments [3] and the current results show this does not affect key parameters such as transformation strain. Fig. 1b shows results using the calibrated model.

\subsubsection{In situ neutron diffraction simulations}

Three post-processing steps were performed to compare simulations and experiments. First, the predicted volume fractions of martensite habit plane variants were converted into volume fractions of martensite correspondence variants and their orientation using the Crystallographic Theory of Martensite (CTM) [47] - in particular, Eq. (17) of Ref. [48] was solved. Second, the martensite volume fractions $v_{N \|}$ and $v_{N \perp}$ were determined, where $\mathbf{N}$ denotes the plane normal of interest (e.g. [ [ $\left.\begin{array}{lll}1 & 0 & 0\end{array}\right]$ or $\left.\left[\begin{array}{lll}0 & 1 & 1\end{array}\right]\right)$ and $\|$ and $\perp$ denote whether $\mathbf{N}$ is parallel or perpendicular to the loading axis. Third, the diffracted intensity $I(\mathbf{N})$ of plane $\mathbf{N}$ was normalized by the intensity $I_{\text {ref }}(\mathbf{N})$ from a reference test case so that

$\frac{I(\mathbf{N})}{I_{r e f}(\mathbf{N})} \propto \frac{v_{N}}{v_{N_{r e f}}}$

Load-biased thermal cycling under a bias stress of $100 \mathrm{MPa}$ was chosen as the reference.

\subsection{Constitutive relation for austenite-martensite aggregates}

The finite element formulation requires a relation between an imposed deformation gradient on an austenite-martensite aggregate and the corresponding increments in average stress, martensite volume fraction and slip system activity. For simulation of entire polycrystals, it is impractical to retain detailed spatial information concerning individual martensite variants; instead, the aggregate is described by the average volume fraction of martensite habit plane variants (plates). The averaging process can be viewed as an isostress approach in that elastic, plastic and transformation processes are driven by a common aggregate Cauchy stress $\mathbf{T}$ and they collectively contribute to the average deformation gradient of the aggregate. These features and improvements to the original formulation [32] are highlighted below.

\subsubsection{Partitioning elastic and inelastic deformation}

Following Lee [49], the deformation gradient $\mathbf{F}=\mathbf{F}^{\mathrm{e}}$ $\mathbf{F}^{\text {inel }}$, so that it is multiplicatively decomposed into a thermo-elastic part $\mathbf{F}^{\mathrm{e}}$ and an inelastic part $\mathbf{F}^{\text {inel }}$. Section 3.2.2 describes how $\mathbf{F}^{\mathrm{e}}$ is related to the Cauchy stress $\mathbf{T}$ and Sections 3.2.3-5 describe how the time derivative of inelastic deformation $\dot{\mathbf{F}}^{\text {inel }}$ is related to $\mathbf{T}$.

\subsubsection{Elastic constitutive relation}

This section highlights modification of the existing theory to incorporate the full elastic anisotropy of the martensite phase, following Ref. [50]. First, the symmetric Piola-Kirchoff stress $\mathbf{T}^{*}$ and Cauchy stress $\mathbf{T}$ are related by

$$
\begin{aligned}
\mathbf{T} & =\frac{1}{\operatorname{det}\left(\mathbf{F}^{\mathrm{e}}\right)} \mathbf{F}^{\mathrm{e}} \mathbf{T}^{*} \mathbf{F}^{\mathrm{T}} \quad \text { where } \quad \mathbf{T}^{*}=\frac{\partial \boldsymbol{\psi}}{\partial \mathbf{E}^{\mathrm{e}}} \\
& =\mathbf{C}\left[\mathbf{E}^{\mathrm{e}}-\mathbf{A}_{\mathrm{th}}\left(\theta-\theta_{0}\right)\right]
\end{aligned}
$$

$\Psi_{\mathrm{R}}$ denotes the Helmholtz free energy of the austenite-martensite aggregate as defined in Eq. (8) of Ref. [32], and the average elastic strain is $\mathbf{E}^{\mathrm{e}}=1 / 2\left(\mathbf{F}^{\mathrm{eT}} \mathbf{F}^{\mathrm{e}}-\mathbf{I}\right)$. Eq. (2) requires the aggregate thermal expansion coefficient $\mathbf{A}_{\mathrm{th}}$ :

$\mathbf{A}_{\mathrm{th}}=v_{\mathrm{A}} \mathbf{A}_{\mathrm{th}-\mathrm{A}}+v_{\mathrm{M}} \mathbf{A}_{\mathrm{th}-\mathrm{M}}$

and effective elastic moduli $\mathbf{C}$ :

$\mathbf{C}=v_{\mathrm{A}} \mathbf{C}_{\mathrm{A}}+\sum_{t=1}^{\mathrm{N}_{\mathrm{T}}} v_{t} \mathbf{C}_{\mathrm{M}(t)} \quad$ where

$\mathbf{C}_{\mathrm{M}(t)}=v_{t, i} \mathbf{C}_{\mathrm{M}(t, i)}+v_{t, j} \mathbf{C}_{\mathrm{M}(t, j)}$

Austenite has cubic symmetry so that $\mathbf{C}_{\mathrm{A}}$ has three independent components. Each habit plate variant $t$ has a local volume fraction $v_{t}$ and elastic modulus $\mathbf{C}_{\mathrm{M}(t)}$, given by the average moduli $\mathbf{C}_{\mathbf{M}(t, i)}, \mathbf{C}_{\mathbf{M}(t, j)}$ and volume fractions $v_{t, i}, v_{t, j}$ $\left(=1-v_{t, i}\right)$ of the monoclinic $\left(\mathrm{B} 19^{\prime}\right)$ correspondence variants $i$ and $j$ within plate $t$. For practical purposes, the components are referred to the austenite crystal basis. This requires the rotation operators $\mathbf{Q}_{t, i}$ and $\mathbf{Q}_{t, j}$ to relate a direction in the martensite crystal basis of variants $i$ and $j$, respectively, to the crystal basis of austenite from which plate $t$ formed. They are obtained by solving Eq. (17) from the CTM [48]:

$\mathbf{Q}_{t, i}=\overline{\mathbf{R}}_{i j} \mathbf{R}_{i j} \mathbf{R}_{\mathrm{LC}-i}$ and $\mathbf{Q}_{t, j}=\overline{\mathbf{R}}_{i j} \mathbf{R}_{\mathrm{LC}_{j}}$

where $\mathbf{R}_{\mathrm{LC}-i}$ and $\mathbf{R}_{\mathrm{LC}-j}$ are the lattice correspondence rotations between martensite variants $i$ and $j$ and austenite, respectively, $\mathbf{R}_{i j}$ is the rotation required to form a twin plane between variants $i$ and $j$, and $\overline{\mathbf{R}}_{i j}$ is the rotation required to form a habit plane with the austenite $[48,50]$. Although the thermal expansion coefficient for martensite plates can be constructed in a similar fashion, the isotropic form $\mathbf{A}_{\mathrm{th}-\mathrm{M}}=\alpha_{\mathrm{M}} \mathbf{I}$ is adopted with the supposition that the primary effect of anisotropy stems from the elastic moduli. This assumption is discussed further in Section 5.2.4 and justified by the small magnitude of thermal strain $(\sim 0.1 \%)$ during thermal cycling [37].

\subsubsection{Average inelastic velocity gradient for the aggregate}

The time derivative of inelastic deformation is $\dot{\mathbf{F}}^{\text {inel }}=\mathbf{L}^{\text {inel }} \mathbf{F}^{\text {inel }}$, where the inelastic velocity gradient of the austenite-martensite aggregate is approximated by a rule of mixtures [32]:

$$
\begin{aligned}
& \mathbf{L}^{\text {inel }}=v_{\mathrm{A}} \sum_{s=1}^{N_{\mathrm{S}}} \dot{\gamma}_{s}\left(\mathbf{b}_{s}^{\text {sip }} \otimes \mathbf{m}_{s}^{\text {slip }}\right)+\sum_{t=1}^{N_{\mathrm{T}}} \dot{v}_{t}\left(\mathbf{b}_{t}^{\text {Trans }} \otimes \mathbf{m}_{t}^{\text {Trans }}\right) ; \\
& v_{\mathrm{A}}=1-v_{\mathrm{M}} \quad \text { and } \quad v_{\mathrm{M}}=\sum_{t=1}^{N_{T}} v_{t}
\end{aligned}
$$


The first term is the contribution from plastic deformation of a volume fraction $v_{\mathrm{A}}$ of austenite having $N_{\mathrm{S}}$ slip systems with Burgers vectors $\mathbf{b}_{s}^{\text {slip }}$, slip plane normals $\mathbf{m}_{s}^{\text {slip }}$ and rates $\dot{\gamma}_{s}$ of slip activities. The second term is the contribution from the rate of increase $\dot{v}_{t}$ in volume fraction of martensite plate type $t\left(=1-N_{\mathrm{T}}\right)$ with habit plane normal $\mathbf{m}_{t}^{\text {trans }}$ and transformation displacement $\mathbf{b}_{t}^{\text {trans }}$. The second equation acknowledges that the austenite plus martensite volume fractions equals 1 , and the third equation indicates that the total martensite volume fraction is the sum of the plate volume fractions. $\dot{\gamma}_{s}$ and $\dot{v}_{t}$ are related to the Piola-Kirchoff stress $\mathbf{T}^{*}$ in Sections 3.2.4 and 3.2.5, respectively.

\subsubsection{Plastic constitutive relation}

The slip rate $\dot{\gamma}_{s}$ in Eq. (6) is specified according to Peirce et al. [33]:

$\dot{\gamma}_{s}=\dot{\gamma}_{0}\left|\frac{\tau_{s}}{g_{s}}\right|^{(1 / \mathrm{m})} \operatorname{sign}\left(\tau_{s}\right) ; \tau_{s}=\mathbf{b}_{s}^{\text {slip }} \cdot\left(\mathbf{F}^{\mathrm{e}^{\mathrm{T}}} \mathbf{F}^{\mathrm{e}} \mathbf{T}^{*}\right) \cdot \mathbf{m}_{s}^{\text {slip }}$

where $\tau_{s}$ is the resolved shear stress on slip system $s, \dot{\gamma}_{0}$ is a reference shear rate, $m$ is the rate sensitivity and $g_{s}$ is the slip system hardness that evolves to a saturation value $g_{\text {sat }}$ according to

$\dot{g}_{s}=\sum_{r=1}^{N_{\mathrm{S}}} h_{r}\left(Q+(1-Q) \delta_{s r}\right)\left|\dot{\gamma}_{r}\right| \quad$ and $h_{r}=h_{0}\left(1-\frac{g_{s}}{g_{\text {sat }}}\right)^{a}$

The self and latent hardening rates are $h_{r}$ and $Q h_{r}$, respectively.

\subsubsection{Transformation constitutive relation}

The rate of change $\dot{v}_{t}$ is determined by ensuring that the unit volume driving force $f_{t}$ to form plate type $t$ is bounded as $-f_{\mathrm{c}} \leqslant f_{\mathrm{t}} \leqslant f_{\mathrm{c}}$, where $f_{c}$ is a critical value and

$$
\begin{aligned}
F_{t}\left(v_{t}, \mathbf{T}, \theta\right)= & \mathbf{b}_{t}^{\text {Trans }} \cdot\left(\mathbf{F}^{\mathrm{e}^{\mathrm{T}}} \mathbf{F}^{\mathrm{e}} \mathbf{T}^{*}\right) \cdot \mathbf{m}_{t}^{\text {Trans }}-\frac{\lambda_{\mathrm{T}}}{\theta_{\mathrm{T}}}\left(\theta-\theta_{\mathrm{T}}\right) \\
& -\sum_{u=1}^{N_{\mathrm{T}}} h_{t u} v_{u}
\end{aligned}
$$

This formalism, proposed by Thamburaja and Anand [13], specifies no change in $v_{t}$ when $f_{t}$ satisfies the inequalities preceding Eq. (9). Should $f_{t}>f_{\mathrm{c}}, v_{t}$ is increased so as to ren$\operatorname{der} f_{t}=f_{\mathrm{c}}$ and if $f_{t}<-f_{\mathrm{c}}, v_{t}$ is decreased so as to render $f_{t}=f_{\mathrm{c}}$. Thus, it is similar to a plastic yield surface.The driving force $f_{t}$ has three terms. The first is the mechanical work of the aggregate stress acting through the transformation strain induced by the formation of plate type $t$. The second is the chemical energy associated with the latent heat of transformation per unit reference volume, $\lambda_{\mathrm{T}}$. The third is the interaction between plates in the aggregate. It represents, for example, the additional contribution to $f_{t}$ due to the stress field of nearby martensite plates $u$; such detailed interactions are not captured by the aggregate stress in the first term.

\section{Calibration of material parameters}

Table 1 shows the material parameters used to simulate the 49.9 at.\% (55 wt.\%) Ni-Ti SMA. They are adopted

Table 1

Calibrated properties for hot rolled/hot drawn polycrystalline 49.9 at. $\% \mathrm{Ni}-\mathrm{Ti}$ ( $55 \mathrm{wt} \% \mathrm{Ni}$ ).

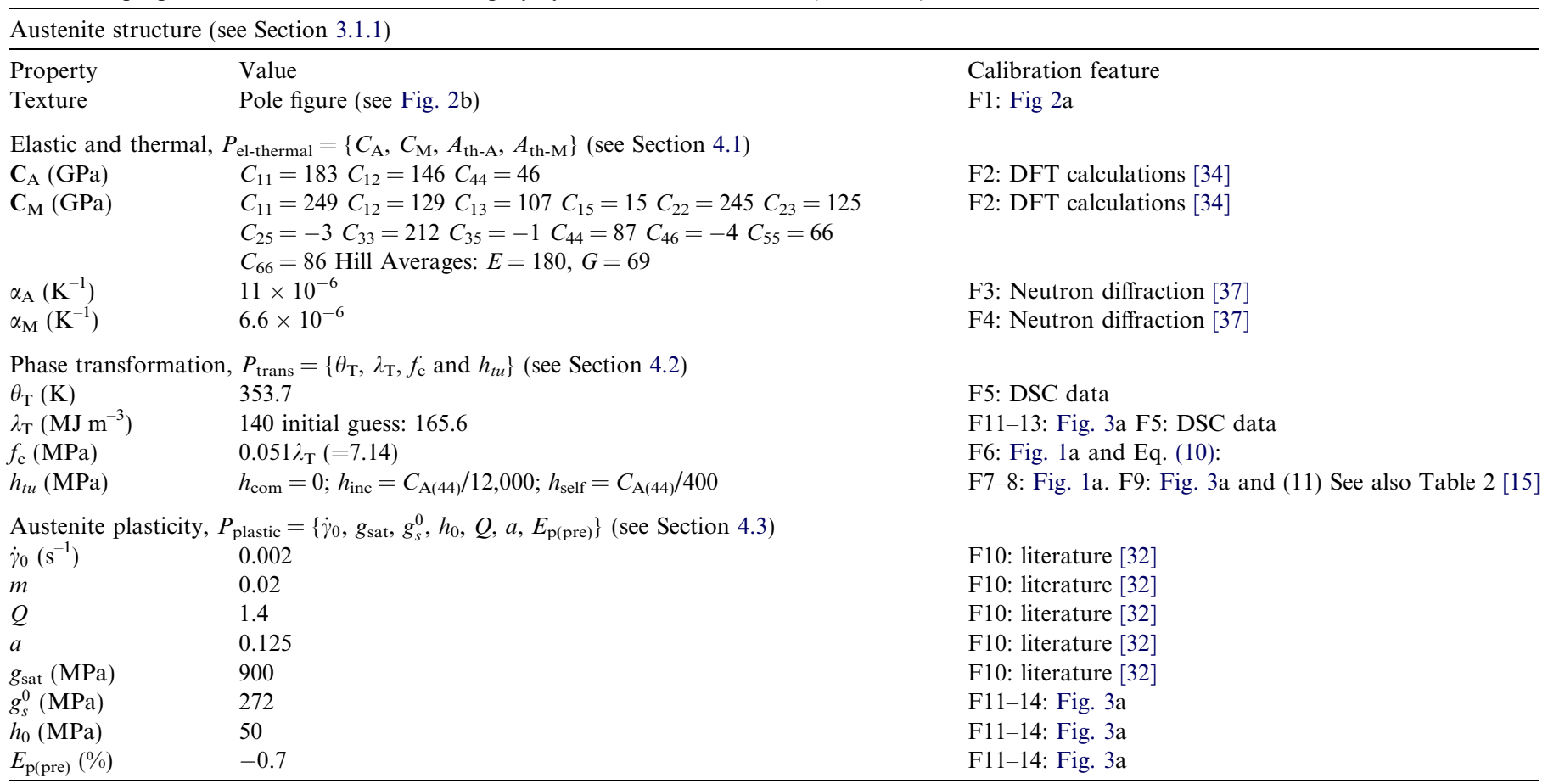




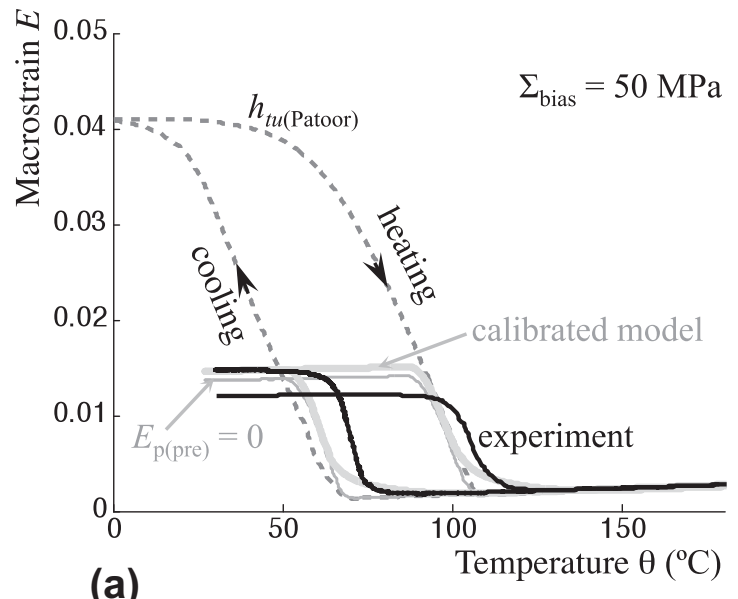

(a)

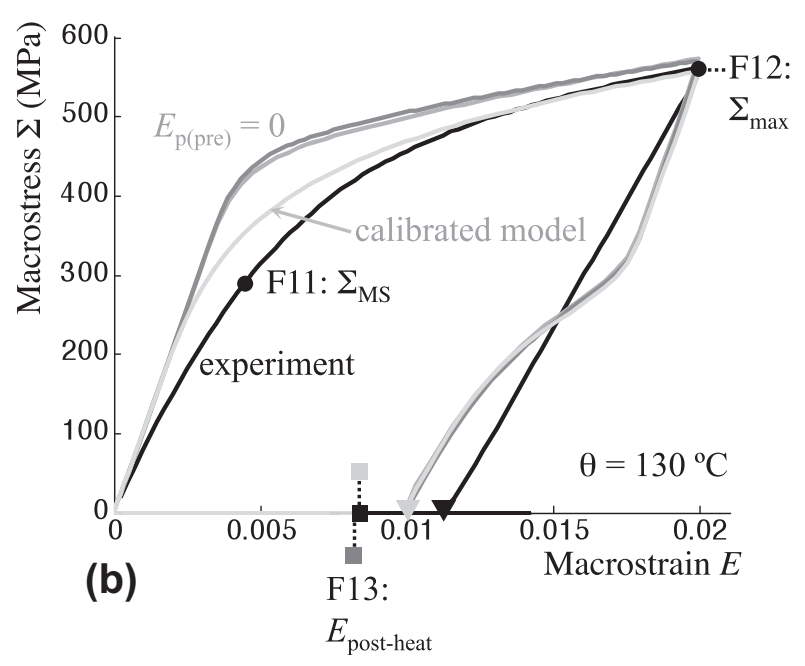

Fig. 4. (a) Axial macrostrain $E$ vs. temperature $\theta$ during thermal cycling with an axial bias stress $\Sigma_{\text {bias }}=50$ MPa and (b) axial macrostress $\Sigma$ vs. macrostrain $E$ at $\theta_{0}=130{ }^{\circ} \mathrm{C}$ for the polycrystalline 49.9 at.\% Ni-Ti alloy. The calibrated model parameters are in Table 1 . Other results in (a) use the calibrated parameters except with the interaction matrix $h_{t u}$ of Patoor et al. [23] or with $E_{\mathrm{p}(\mathrm{pre})}=0$. The $E_{\mathrm{p}(\text { pre) }}=0$ cases in (b) are nearly coincident and use $\left(g_{s}^{0}, h_{0}\right)=(235 \mathrm{MPa}, 500 \mathrm{MPa})$ vs. (250 MPa, $\left.50 \mathrm{MPa}\right)$ (the former is slightly higher).

from published literature values or calibrated to DSC data and select isothermal deformation and thermal cycling tests performed specifically to support this modeling effort. These various "features" and the calibration process are described in Sections 4.1-4.3.

\subsection{Elastic-thermal, $P_{\text {el-thermal }}=\left\{C_{A}, C_{M}, A_{\text {th-A }}, A_{\text {th-M }}\right\}$}

The anisotropic elastic stiffness $\mathbf{C}_{\mathrm{A}}$ for the cubic (B2) austenite phase and $\mathbf{C}_{\mathbf{M}}$ for the monoclinic (B19') martensite phase are adopted from the density functional theory calculations (feature F2, Table 1) of Hatcher et al. [34]. Isotropic thermal expansion properties are assumed with $\alpha_{\mathrm{A}}$ and $\alpha_{M}$ taken from the neutron diffraction experiments (feature F3, Table 1) of Qiu et al. [37]. Use of recently computed elastic moduli corrects frequent assumptions in the literature that $\mathbf{C}_{\mathrm{M}} \sim 1 / 2 \mathbf{C}_{\mathrm{A}}$ (e.g. $\left.[12,13]\right)$ or $\mathbf{C}_{\mathrm{M}} \leqslant \mathbf{C}_{\mathrm{A}}$ (e.g. $[7,9,15-18]$. These effects, including differences in moduli from Hatcher et al. [34] vs. Wagner et al. [51], are discussed in Section 5.2.4.

\subsection{Transformation, $P_{\text {trans }}=\left\{\theta_{T}, \lambda_{T}, f_{c}\right.$ and $\left.h_{t u}\right\}$}

This study models $N_{\mathrm{T}}=24$ type-II twinned martensite plate types, like many micromechanics-based models [13,15-17,26], although there are 192 theoretically possible habit plane variants (hpv) for $\mathrm{B} 2 \rightarrow \mathrm{B} 19^{\prime}$ transformation [47]. The transformation parameters $P_{\text {trans }}$ are obtained from a combination of DSC (no load), isothermal deformation tests and thermal cycling data at $\Sigma_{\text {bias }}=50 \mathrm{MPa}$. The DSC data (averaged over seven samples) gives $\theta_{\mathrm{MF}}, \theta_{\mathrm{MS}}$, $\theta_{\mathrm{AS}}$ and $\theta_{\mathrm{AF}}=46,71,86$ and $109 \pm 2{ }^{\circ} \mathrm{C}$, respectively, for this 49 at.\% Ni-Ti alloy. These values (feature F4) furnish the transformation temperature $\theta_{\mathrm{T}}=\left(\theta_{\mathrm{MS}}+\theta_{\mathrm{AS}}\right) /$ $2=353.7 \mathrm{~K}$ (standard deviation $=2 \mathrm{~K}$ ). The calibrated simulations use a latent heat of transformation
$\lambda_{\mathrm{T}}=140 \mathrm{MJ} \mathrm{m}^{-3}$, as detailed in Section 4.3. Initially, an average of $Q_{\mathrm{DSC}}$ (feature F5) for the forward $\mathrm{A} \rightarrow \mathrm{M}$ and reverse $\mathrm{M} \rightarrow \mathrm{A}$ heats of transformation is used, yielding $\lambda_{\mathrm{T}} \approx Q_{\mathrm{DSC}}=165.6 \mathrm{MJ} \mathrm{m}^{-3}$ (standard deviation $=$ $4.7 \mathrm{MJ} \mathrm{m}^{-3}$ ). This is viewed as an initial guess since $Q_{\mathrm{DSC}}$ includes contributions from elastic or defect energies associated with the transformation.

The critical driving force for transformation is obtained from

$\frac{f_{\mathrm{c}}}{\lambda_{\mathrm{T}}}=\frac{\theta^{\mathrm{M} \rightarrow \mathrm{A}}-\theta^{\mathrm{A} \rightarrow \mathrm{M}}}{2 \theta_{\mathrm{T}}}=\frac{\Delta \theta_{\mathrm{H}}}{2 \theta_{\mathrm{T}}}$

Eq. (10) is obtained by writing the forward $\left(f_{t}^{\mathrm{A} \rightarrow \mathrm{M}}=f_{\mathrm{c}}\right)$ and backward $\left(f_{t}^{\mathrm{M} \rightarrow \mathrm{A}}=-f_{\mathrm{c}}\right)$ critical conditions in extended form using Eq. (9) and then taking the difference between them. Eq. (10) furnishes $f_{c} / \lambda_{\mathrm{T}}=0.051$, based on an average hysteretic width (feature F6) $\Delta \theta_{\mathrm{H}}=36.3 \mathrm{~K}$ (standard deviation $=1.15 \mathrm{~K}$ ) for thermal cycling at $\Sigma_{\text {bias }}=50 \mathrm{MPa}$ (see Fig. 1a). This small $\Sigma_{\text {bias }}$ minimizes plasticity; a similar $f_{\mathrm{c}} /$ $\lambda_{\mathrm{T}}$ value occurs with $\Sigma_{\text {bias }}=0$ data. Formally, $\Delta \theta_{\mathrm{H}}$ is an average width over the range $\xi=0.1-0.9$, where $\xi$ is the fraction of transformation strain.

The structure of the martensite plate interaction matrix $h_{t u}$ in Eq. (9) is obtained by calibrating the simulations to give $E_{\mathrm{T}} \approx 1 \%$ (feature $\mathbf{F} 7$ ) and $\Delta \theta^{\mathrm{A} \rightarrow \mathrm{M}} \approx 25^{\circ} \mathrm{C}$ (feature F8) at $\Sigma_{\text {bias }}=50 \mathrm{MPa} . \Delta \theta^{\mathrm{A} \rightarrow \mathrm{M}}$ is the decrease $\left(\theta_{\mathrm{MF}}-\theta_{\mathrm{MS}}\right)$ in temperature to complete the $\mathrm{A} \rightarrow \mathrm{M}$ transformation. The outcome is that $h_{t u}$ must have three independent values:

$h_{t u}= \begin{cases}h_{\mathrm{self}}\left(=C_{\mathrm{A}(44)} / 400\right) & \text { if } t=u \\ h_{\mathrm{com}}(=0) & \text { if } t \neq u \text { and } \operatorname{det}\left(\epsilon_{\mathrm{T}(t)}-\epsilon_{\mathrm{T}(u)}\right)=0 \\ h_{\mathrm{in}}\left(=C_{\mathrm{A}(44)} / 12000\right) & \text { if } t \neq u \text { and } \operatorname{det}\left(\epsilon_{\mathrm{T}(t)}-\epsilon_{\mathrm{T}(u)}\right) \neq 0\end{cases}$

This structure is a modification to the popular form proposed by Patoor et al. [23], where $h_{\text {self }}=h_{\text {com }}=$ 
$C_{\mathrm{A}(44)} / 3000 \mathrm{MPa}$ and $h_{\mathrm{inc}}=C_{\mathrm{A}(44)} / 750 \mathrm{MPa}$ are used for NiTi [15-17]. The rationale for the modification is that simulations employing the Patoor et al. [23] structure (curve $h_{t u \text { (Patoor) }}$, Fig. 4 a) give $E_{\mathrm{T}} \sim 4 \%$ for $\Sigma_{\text {bias }}=50 \mathrm{MPa}$, and thus over-predict the experimental values, regardless of the assumed $C_{\mathrm{A}(44)}$ value. Martensite plates with maximal transformation strain along the loading axis dominate over other plate types because the stress work (term 1 in $f_{t}$, Eq. (9)) initially renders the driving force $f_{+}$largest for this favored (+) plate type. As long as $h_{\text {com }}<h_{\text {inc }}$, the favored $(+)$ plates experience less hardening than non-favored $(-)$ plates, because $-\partial f_{+} / \partial v_{+}<\partial f_{-} / \partial v_{+}$. The modification sets $h_{\text {self }} \gg h_{\text {com }}, h_{\text {inc }}$ to suppress formation of a single plate type.

The calibration is guided by application of Eq. (9) to an idealized case of two populations of plate types: a favored $(+)$ type that renders a transformation strain $E_{\mathrm{T}(\max )}$ if $v_{+} \rightarrow 1$ and a non-favored (-) collection of self-accommodating plate types that renders $E_{\mathrm{T}} \sim 0$ if $v_{-} \rightarrow 1$. Taking the difference between the critical force conditions $f_{+}=f_{\mathrm{c}}$ and $f_{-}=f_{\mathrm{c}}$ furnishes

$S_{+} \sum_{\text {bias }}=\frac{\Delta h_{+-}}{2}\left(\frac{\sigma_{\mathrm{T}}}{\sigma_{\mathrm{T}}^{\max }}+1\right)+\frac{\Delta h_{-+}}{2}\left(\frac{\sigma_{\mathrm{T}}}{\sigma_{\mathrm{T}}^{\max }}-1\right)$

where $S_{+} \Sigma_{\text {bias }}$ is the aggregate stress work to form favored plates and $\Delta h_{+-}=h_{++}-h_{-+}$and $\Delta h_{-+}=h_{--}-h_{+-}$are differences in interaction elements. Thus, increases in the differences $\left(h_{\text {self }}-h_{\text {com }}\right)$ and $\left(h_{\text {self }}-h_{\text {inc }}\right)$ increase the required $S_{+} \Sigma_{\text {bias }}$ for favored plates, decreasing $E_{\mathrm{T}}$. Eq. (9) also furnishes

$\lambda_{\mathrm{T}} \frac{\theta_{\mathrm{MS}}-\theta_{\mathrm{MF}}}{\theta_{\mathrm{T}}}=\frac{\Delta h_{++}}{\Delta h_{+-}+\Delta h_{-+}}\left(S_{+} \sum_{\text {bias }}+\Delta h_{-+}\right)+h_{+-} \quad$ and

$\sum_{\max }-\sum_{\mathrm{MS}} \approx \frac{h_{\text {self }}}{S_{+}}$

where $h_{++}=h_{++}-h_{+-}$. The second equation of Eqs. (13) suggests that $h_{\text {self }}$ can be determined from the difference, $\Sigma_{\max }-\Sigma_{\mathrm{MS}}$ (feature $\mathbf{F 9}$ ), from isothermal deformation tests (Fig. 3a). Further, Eq. (12) and the first equation of Eqs. (13) suggest that differences such as $h_{\text {self }}-h_{\text {com }}$ and $h_{\text {self }}-h_{\text {inc }}$ can be determined by capturing Features F7 and F8 for thermal cycling at low bias stress (Fig. 1a). The final results reported in Eq. (11) and Table 1 are obtained as a best fit.

\subsection{Austenite plasticity, $P_{\text {plastic }}=\left\{\dot{\gamma}_{0}, m, g_{s}^{0}, g_{s a t}, h_{0}, Q, a\right.$, $\left.E_{p(\text { pre })}\right\}$ and $\lambda_{T}$ update}

These parameters are obtained from literature values and additional isothermal deformation data. In particular, $6\left\{\begin{array}{lll}1 & 1 & 0\end{array}\right\} /\left\langle\begin{array}{llll}1 & 0 & 0\rangle\end{array}\right.$ and $6\left\{\begin{array}{llll}0 & 0 & 1\end{array}\right\} /\left\langle\begin{array}{llll}1 & 0 & 0\rangle\end{array}\right.$ austenitic slip systems are considered [52]. The rate sensitivity $m=0.02$, reference strain rate $\dot{\gamma}_{0}=10^{-3} \mathrm{~s}^{-1}\left(\dot{E} \geqslant 10^{-4} \mathrm{~s}^{-1}\right), Q=1.4$, $a=0.125$ and $g_{\text {sat }}=900 \mathrm{MPa}$ (see Eqs. (7) and (8)) are adopted from prior calibration of the model to single crystal pseudoelastic compression tests (feature F10), using loading orientations that enhance plasticity [32]. In reality, there is limited data to determine these parameters accurately, but the simulations are less sensitive to them. The remaining plasticity parameters are the threshold resolved shear stress $g_{s}^{0}$ for plastic flow, initial strain hardening $h_{0}$ and plastic pre-deformation $E_{\mathrm{p}(\mathrm{pre})}$. The resulting calibration gives a best fit of $g_{s}^{0}=272 \mathrm{MPa}, h_{0}=50 \mathrm{MPa}, E_{\mathrm{p}(\text { pre })}$ $=-0.7 \%$ and $\lambda_{\mathrm{T}}=140 \mathrm{MJ} \mathrm{m}^{-3}$ (updated from an initial guess $165.6 \mathrm{MJ} \mathrm{m}^{-3}$ ).

More specifically, the calibration procedure matches $\Sigma_{\mathrm{MS}}, \Sigma_{\max }$ and $E_{\text {post-heat }}=0.0085$ for $E_{\max }=0.02$ (Features F11-13, Fig. 4b). The updated, smaller $\lambda_{\mathrm{T}}$ decreases $\Sigma_{\mathrm{MS}}$ and $\Sigma_{\max }$ to better match the data, but $g_{s}^{0}$ and $h_{0}$ are indeterminant. For example, the same curve $\left(E_{\mathrm{p}(\mathrm{pre})}=0\right.$, Fig. $4 \mathrm{~b})$ is obtained for $\left(g_{s}^{0}, h_{0}\right)=(250 \mathrm{MPa}, 50 \mathrm{MPa})$ vs. (235 MPa, $500 \mathrm{MPa})$. The first case is selected since it better matches $E_{\text {post-heat }}=0.0204$ (feature F14, Fig. 3a). The second case under predicts the value.

A final issue is that curve $E_{\mathrm{p}(\text { pre })}=0$ (Fig. $4 \mathrm{~b}$ ) over predicts $\Sigma_{\mathrm{MS}}$ (feature F11). Prior work [32] demonstrates that compressive prestraining decreases $\Sigma_{\mathrm{MS}}$ and increases hardening. The "calibrated model" result (Fig. 4b) adopts $E_{\mathrm{p}(\text { pre) }}=-0.7 \%$ and $\left(g_{s}^{0}, h_{0}\right)=(272 \mathrm{MPa}, 50 \mathrm{MPa})$ as a best match. A larger compressive prestrain does not improve the match. This pre-deformation produces a multi-axial and spatially varying residual stress distribution with stress in the loading direction varying from $-345 \mathrm{MPa}$ to $272 \mathrm{MPa}$. These magnitudes are a substantial fraction of $\Sigma_{\mathrm{MS}}$ (feature F11) in Fig. 3a.

\section{Model assessment}

\subsection{Isothermal deformation response}

The calibrated model captures the monotonic loading paths for different $E_{\max }$ and $\theta$. In particular, $\Sigma_{\max }$ for $\theta=130{ }^{\circ} \mathrm{C}$ (Pt A, Fig. 3b) agrees with experiments. Also, both experiments and simulations show an upward shift $\Delta \Sigma \sim 100 \mathrm{MPa}$ when $\theta$ increases to $215^{\circ} \mathrm{C}$ (Fig. 3b). If plasticity is "turned off" in the simulations, an excessive shift $\Delta \Sigma=627 \mathrm{MPa}$ occurs. This is consistent with a Clausius-Clapeyron slope $\mathrm{d} \Sigma / \mathrm{d} \theta=6.2 \mathrm{MPa} \mathrm{K}^{-1}$ for favorably oriented martensite plates $[15,53]$. The simulations show that plasticity intervenes to lower the shift; it is driven by complex, multi-axial stress states inherent in polycrystals.

The discrepancy between the experimental and simulated unloading paths suggests that the reverse $(\mathrm{M} \rightarrow \mathrm{A})$ transformation is complex. The experimental unloading paths are relatively linear (Fig. 3a), with most of the stress-induced martensite recovered during subsequent heating rather than during unloading. The simulated unloading path $\left(\theta=130^{\circ} \mathrm{C}\right.$, Fig. 3b) is the opposite, with most of the stress-induced martensite recovered during unloading rather than heating. A possible interpretation is that the simulations underestimate $f_{\mathrm{c}}$ for the reverse transformation. This might be due to coupling between 
plasticity and transformation at fine (variant) scales - a phenomenon not captured explicitly by the aggregate formulation.

\subsection{Thermal cycling response}

Overall, several experimental trends are captured, including the textured nature of martensite, but again there are quantitative discrepancies.

\subsubsection{Effect of bias stress and prestrain on transformation strain and critical temperatures}

Consistent with experiments, the predicted transformation strain $E_{\mathrm{T}}$ increases with $\Sigma_{\text {bias }}$, as do the critical temperatures $\theta_{\mathrm{AS}}, \theta_{\mathrm{AF}}, \theta_{\mathrm{MS}}$ and $\theta_{\mathrm{MF}}$, and the temperature difference $\theta_{\mathrm{MS}}-\theta_{\mathrm{MF}}$ (Fig. 1). Fig. 5 shows that even the two-way response for thermal cycling at $\Sigma_{\text {bias }}=0$ is captured. This demonstrates that a plastic predeformation $E_{\mathrm{p}(\text { pre })}=-0.7 \%$ creates a positive $E_{\mathrm{T}}$, by inducing an internal stress state that biases martensite plate formation. Conversely, a negative $E_{\mathrm{T}}$ is generated for $E_{\mathrm{p}(\text { pre })}>0$. It is interesting that a nonzero $E_{\mathrm{T}}$ occurs, even though the average internal stress is zero.

Fig. 6 shows that the simulations capture a peak in $E_{\mathrm{T}}$ with $\Sigma_{\text {bias. }}$. This is due primarily to the new proposed structure for $h_{t u}$ (Eq. (11)) and the coupling of crystal plasticity and transformation (Eq. (6)). These features cause $E_{\mathrm{T}}$ to increase gradually with $\Sigma_{\text {bias }}$ due to formation of the favored (+) martensite. For $\Sigma_{\text {bias }}>350 \mathrm{MPa}$, the model predicts a decrease in $E_{\mathrm{T}}$ with $\Sigma_{\text {bias }}$ due to the onset of open loop strain, $\Delta E_{\text {cycle }}$ (see Fig. 8). The predicted effect of $E_{\mathrm{p}(\text { pre })}=-0.7 \%$ vs. 0 on the $E_{\mathrm{T}}-\Sigma_{\text {bias }}$ response in Fig. 6 is negligible. For comparison, simulations using the Patoor et al. [23] structure for $h_{t u}$ substantially overestimate $E_{\mathrm{T}}$ at small $\Sigma_{\text {bias }}$ (curve $h_{t u(\text { (Patoor) }}$, Fig. 6) and predict $E_{\mathrm{T}}$ to be relatively independent of $\Sigma_{\text {bias }}$, contrary to these and previous experimental results $[1-3,30]$.

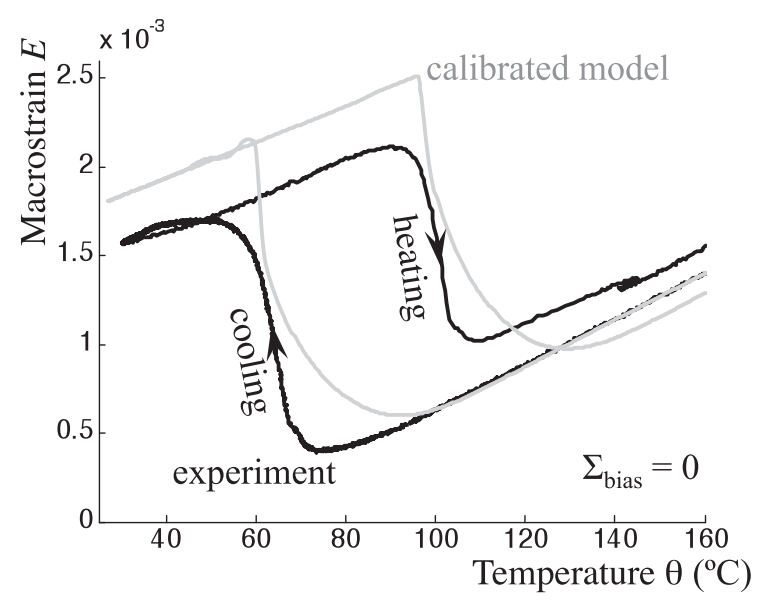

Fig. 5. Axial macrostrain $E$ vs. temperature $\theta$ during no-load thermal cycling of the polycrystalline 49.9 at.\% Ni-Ti alloy, showing a two-way effect. The calibrated model parameters are presented in Table 1.

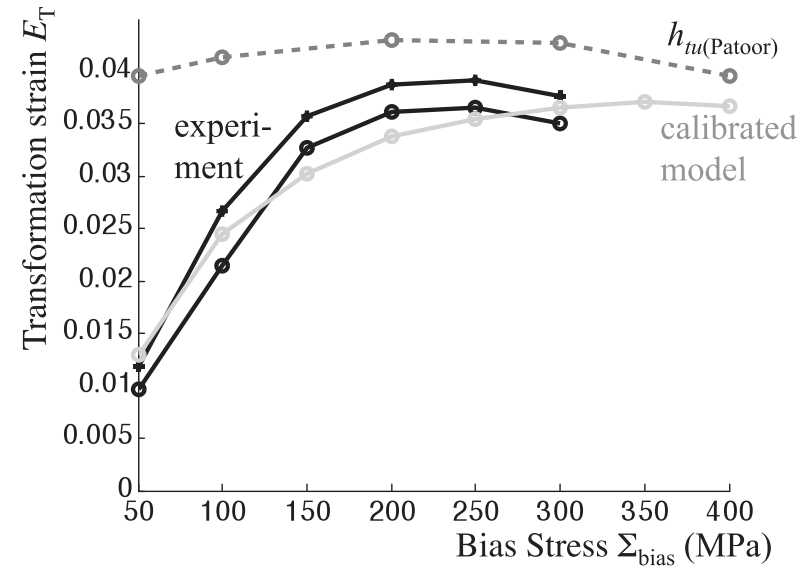

Fig. 6. Axial transformation strain $E_{\mathrm{T}}$ vs. bias stress $\Sigma_{\text {bias }}$ during thermal cycling between $\theta_{\min }=30^{\circ} \mathrm{C}$ and $\theta_{\max }=165^{\circ} \mathrm{C}$ (lower experimental curve) vs. $200^{\circ} \mathrm{C}$ (upper experimental curve) for the polycrystalline 49.9 at. $\% \mathrm{Ni}-\mathrm{Ti}$ alloy. The calibrated model parameters are presented in Table 1. Also shown is the calibrated model result using the interaction matrix $h_{t u}$ of Patoor et al. [23]. The model results are insensitive to $\theta_{\max }=165$ vs. $200{ }^{\circ} \mathrm{C}$.

\subsubsection{Plastic strain enhancement due to phase transformation}

Simulations of thermal cycling at large $\Sigma_{\text {bias }}(400 \mathrm{MPa})$ reveal that transformation enhances the macroscopic plastic strain $E_{\mathrm{p}}$. Fig. 7 shows rather modest increases in $E_{\mathrm{p}}$ with thermal cycling for the "plasticity only" case - where transformation is turned off. In contrast, $E_{\mathrm{p}}$ is larger in the "calibrated model" case, where both transformation and plasticity are present. The largest increases in $E_{\mathrm{p}}$ occur during the early stages of cooling and latter stages of heating, when $v_{\mathrm{M}}$ is small (see regions 1 and 2, Fig. 7). The phenomenon is reminiscent of ratcheting of $E_{\mathrm{p}}$ during stress-biased thermal cycling of composites with a large thermal strain mismatch between constituents [54]. These predictions are consistent with prior work [32] showing that plasticity aids

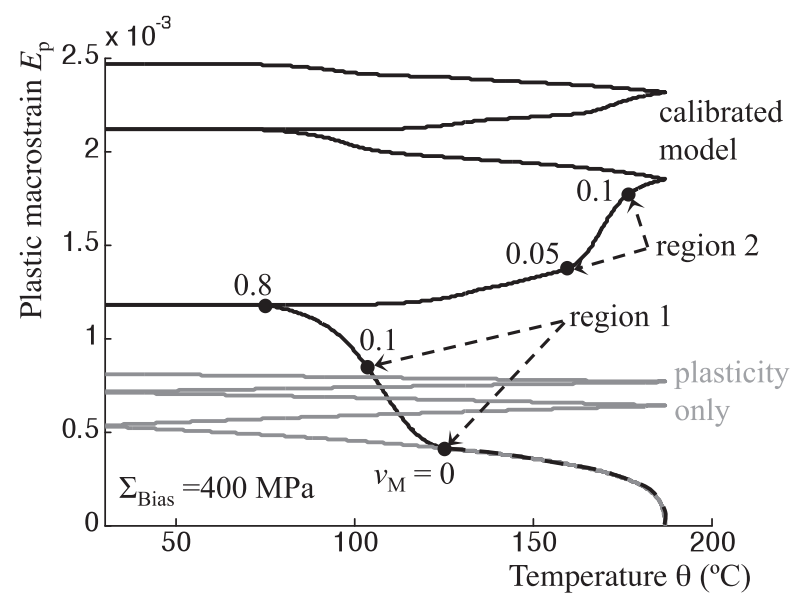

Fig. 7. Predicted axial plastic macrostrain $E_{\mathrm{p}}$ vs. temperature $\theta$ during thermal cycling with an axial bias stress $\Sigma_{\text {bias }}=400 \mathrm{MPa}$. The calibrated model parameters are presented in Table 1 . The "plasticity only" case uses the calibrated model without any phase transformations. 


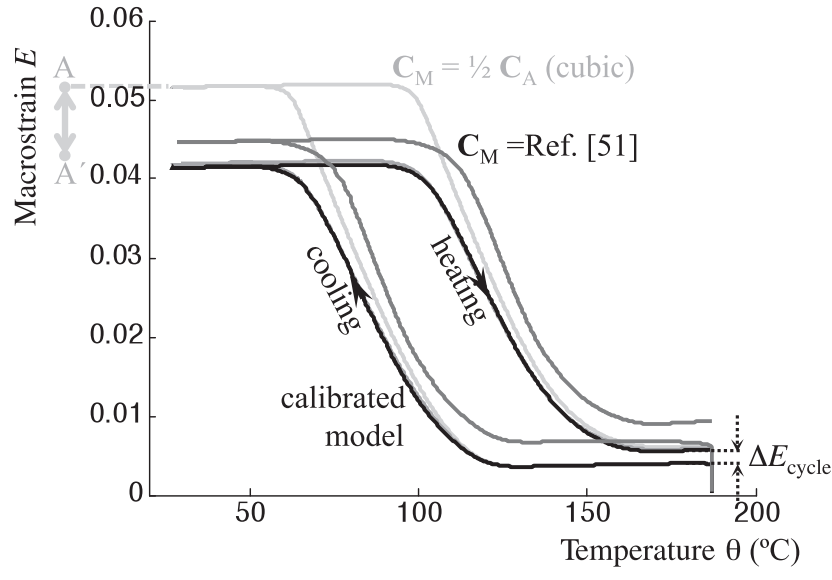

Fig. 8. Axial macrostrain $E$ vs. temperature $\theta$ during thermal cycling with an axial bias stress $\Sigma_{\text {bias }}=400 \mathrm{MPa}$, showing predictions of the calibrated model, which uses elastic constants $\mathbf{C}_{M}$ and $\mathbf{C}_{A}$ from Ref. [34]. Also shown are the calibrated model predictions with $\mathbf{C}_{\mathrm{M}} \sim 1 / 2 \mathbf{C}_{\mathrm{A}}, \mathbf{C}_{\mathrm{M}}$ and $\mathbf{C}_{\mathrm{A}}$ from

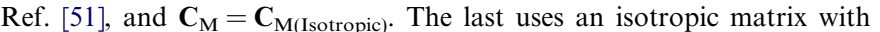
Young's modulus $E$ and elastic shear modulus $G$ given by the Hill averages (Table 1). It overlaps the original calibrated model result.

martensite transformation during pseudoelastic loading to some macroscopic stress $\Sigma$.

\subsubsection{Discrepancy in open loop strain}

An important quantitative discrepancy is the underestimate of incremental strain per thermal cycle, $\Delta E_{\text {cycle, or }}$ "open loop strain" (Fig. 1). Although transformation is predicted to enhance plasticity, the simulations predict noticeable $\Delta E_{\text {cycle }}$ values only at large $\Sigma_{\text {bias }}(>350 \mathrm{MPa})$ while experiments show noticeable values even at small $\Sigma_{\text {bias }}(50 \mathrm{MPa})$. This discrepancy may be due to the nature of the "aggregate" constitutive relation (Section 3.2.3) and the assumption that the rate of slip activity $\left(\dot{\gamma}_{s}\right.$, Section 3.2.4) and rate of martensite formation $\left(\dot{v}_{t}\right.$, Section 3.2.5) are both computed from the average aggregate stress. In reality, the local stress field around martensite plates can be sufficiently large to drive local plasticity, as evidenced by recent transmission electron microscopy of dislocation content in micron-scale, pseudoelastically compressed single crystals [27] and load-biased thermal cycling of larger single crystals [30].

\subsubsection{Assumptions concerning martensite elastic moduli and thermal expansion coefficients}

The simulations reveal several aspects concerning elastic moduli and thermal expansion coefficients. First, Fig. 8 shows that the predicted transformation strain $E_{\mathrm{T}}$ during thermal cycling is about 0.01 greater if a common assumption, $\mathbf{C}_{\mathrm{M}} \sim 1 / 2 \mathbf{C}_{\mathrm{A}}$, is used (e.g. [12,13]). This assumption is erroneous since both experiments $[55,56]$ and first principle calculations [34,51] show that martensite is stiffer than austenite (Table 1). A more compliant martensite increases $E_{\mathrm{T}}$ by increasing the elastic strain and texturing in the martensite; the former is deduced from the unloading path from $A$ to $A^{\prime}$ in Fig. 8. A reasonable approximation to the calibrated results is to use $\mathbf{C}_{M}=\mathbf{C}_{\mathrm{M} \text { (isotropic), where }}$ $\mathbf{C}_{\mathrm{M} \text { (isotropic) }}$ is an isotropic matrix with Young's and shear moduli given by Hill's averages (see Table 1). The results are based on the anisotropic moduli of Hatcher et al. [34]. If values from Wagner and Windl [51] are used, smaller Hill's averages result ( $\left.E_{\mathrm{h}}=122 \mathrm{GPa}, G_{\mathrm{h}}=45 \mathrm{GPa}\right)$, but $\mathbf{C}_{\mathrm{A}}$ is also smaller. The net effect is a $\sim 0.3 \%$ increase in $E_{\mathrm{T}}$ (Fig. 8), i.e. it is virtually unchanged. The observation that martensite can be represented by average isotropic elastic moduli suggests that it is also reasonable to use isotropic thermal expansion coefficients, at least for aggregate-scale simulations. This supports the adoption of isotropic descriptions for $\mathbf{A}_{\mathrm{th}-\mathrm{A}}$ and $\mathbf{A}_{\mathrm{th}-\mathrm{M}}$ in Section 4.1.

\subsubsection{Texture evolution}

The calibrated simulations are qualitatively consistent with measurements of textured martensite formation
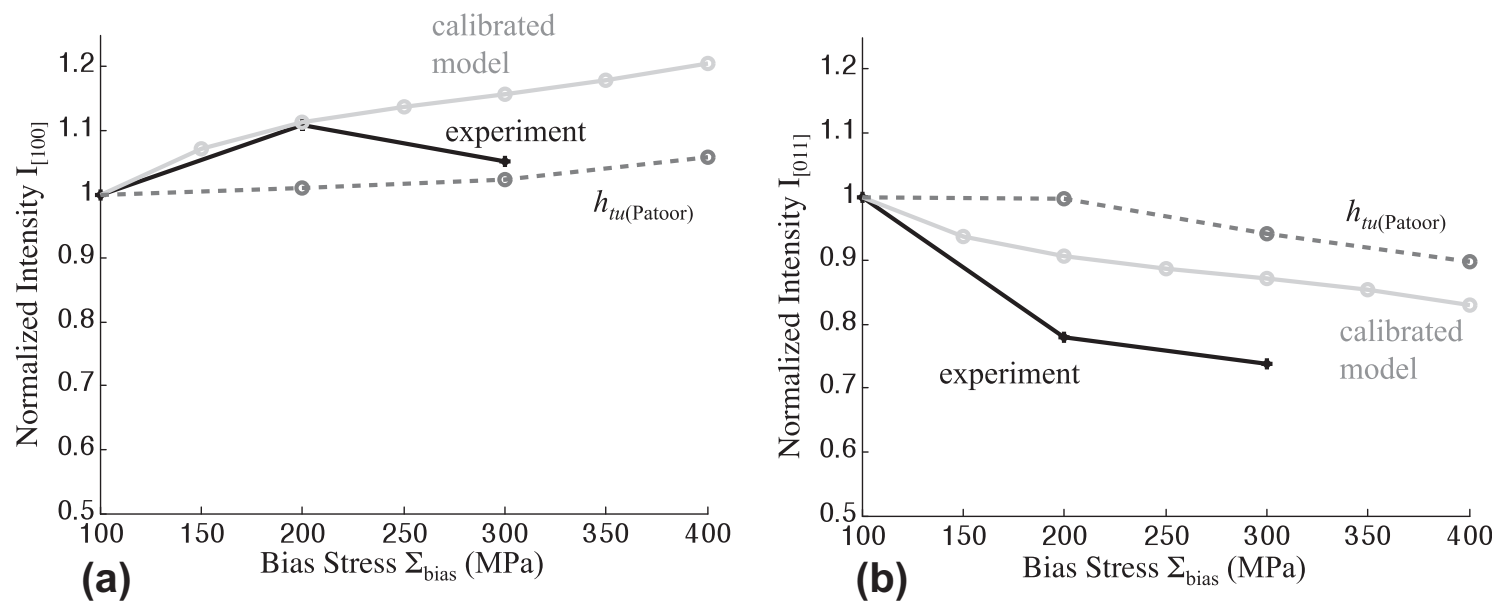

Fig. 9. Normalized neutron diffraction intensities $I$ vs. bias stress $\Sigma_{\text {bias }}$ for (a) $\left(\begin{array}{lll}1 & 0 & 0\end{array}\right)$ and (b) $\left(\begin{array}{lll}0 & 1 & 1\end{array}\right)$ martensite planes oriented parallel to the loading axis, for the 49.9 at. $\% \mathrm{Ni}-\mathrm{Ti}$ alloy. The intensities are measured at $\theta_{\min }=30^{\circ} \mathrm{C}$, following thermal cycling to $\theta_{\max }=230^{\circ} \mathrm{C}$, and are normalized by the intensity at $\Sigma_{\text {bias }}=100 \mathrm{MPa}$. The experimental data is from Ref. [2]. The calibrated model parameters are presented in Table 1. Also shown is the calibrated model result using the interaction matrix $h_{t u}$ of Patoor et al. [23]. 
during thermal cycling at $\Sigma_{\text {bias }}=-150 \mathrm{MPa}$. During heating to $130{ }^{\circ} \mathrm{C}$, in situ neutron diffraction reveals peaks from retained martensite with plane normals $\mathbf{N}=\left[\begin{array}{lll}0 & 1 & 1\end{array}\right] \perp$ to the loading axis and also $\mathbf{N}=\left[\begin{array}{lll}1 & 0 & 0\end{array}\right] \|$ to the loading axis. Martensite with $\mathbf{N}=\left[\begin{array}{lll}0 & 1 & 1\end{array}\right] \|$ or $\mathbf{N}=\left[\begin{array}{lll}1 & 0 & 0\end{array}\right] \perp$ is not observed [56]. The calibrated model predicts the same results at $130{ }^{\circ} \mathrm{C}$; in particular, there is $5 \%$ retained martensite, some of which has $\mathbf{N}=\left[\begin{array}{lll}0 & 1 & 1\end{array}\right] \perp$ and $\mathbf{N}=\left[\begin{array}{lll}1 & 0 & 0\end{array}\right] \|$, but none has $\mathbf{N}=\left[\begin{array}{lll}0 & 1 & 1\end{array}\right] \|$ or $\mathbf{N}=\left[\begin{array}{lll}1 & 0 & 0\end{array}\right] \perp$. This complements earlier work by Gao et al. [57], where isothermal loading was considered instead of thermal cycling.

Fig. 9 shows that the calibrated model qualitatively captures the relative trends in $\left[\begin{array}{lll}1 & 0 & 0\end{array}\right] \|$ and $\left[\begin{array}{lll}0 & 1 & 1\end{array}\right] \|$ intensities with increasing $\Sigma_{\text {bias. }}$. The intensities are measured at $\theta_{\min }=30^{\circ} \mathrm{C}$ and are normalized by values at $\Sigma_{\text {bias }}=100 \mathrm{MPa}$. The simulation results depend slightly on $E_{\mathrm{p}(\mathrm{pre})}$ because the residual stress state aids or opposes the bias stress, depending on the location. For example, the normalized intensity $\left[\begin{array}{lll}1 & 0 & 0\end{array}\right]$ shifts downward by $\sim 0.03$ for $E_{\mathrm{p}(\text { pre })}=0$ (vs. $-0.7 \%$ ) and [ $\left.\begin{array}{lll}0 & 1 & 1\end{array}\right]$ is unchanged. Results using the hardening matrix of Patoor et al. [23] (see the discussion following Eq. (11)) tend to be less dependent on $\Sigma_{\text {bias }}$ because the martensite texture is over-predicted at small $\Sigma_{\text {bias }}$, leaving little room for additional texturing at larger $\Sigma_{\text {bias. }}$.

\section{Conclusions}

Several key elements are required to capture the thermal cycling and isothermal deformation trends for polycrystalline NiTi (49.9 at.\% Ni). A critical feature is the coupling of transformation and plasticity. With appropriate data, the calibrated model captures (i) the effect of temperature on isothermal deformation loading response; (ii) the effect of bias stress on critical temperatures, transformation strain and martensite texture evolution during thermal cycling; and (iii) the effect of deformation processing in the austenitic state on the two-way effect and uniaxial loading at $\theta>\theta_{\mathrm{AF}}$.

Two other key elements are the incorporation of anisotropic elasticity and an augmented form of the martensite hardening matrix $h_{t u}$ (Eq. (11)). The first corrects a frequent assumption that martensite moduli are $\sim 1 / 2$ those of austenite. The augmented $h_{t u}$ (Eq. (11)) increases the self-hardening term, thereby capturing the gradual increase in transformation strain and martensite texture with bias stress during thermal cycling.

The simulations capture plasticity-transformation coupling in an aggregate sense but not on the martensite plate scale. On this smaller scale, retained martensite can affect texture evolution, and the stress redistribution in the vicinity of the plates may promote dislocation substructure [27-30] and affect the critical driving force for martensite formation $\left(f_{c}\right.$, Eq. (9)). Some consequences are discrepancies in the amount of reverse transformation during unloading and subsequent heat treatment (Fig. 3), the magnitude of ratcheting during thermal cycling under a bias stress (Fig. 1), and the effect of upper cycle temperature on transformation strain (Fig. 6) [2]. In principle, the use of 24 type II rather than all 192 predicted type I and type II habit plane variants [48] may affect martensite texture predictions, but it is unlikely to address the aforementioned discrepancies.

Concerning future activities, the present work could benefit, in principle, from detailed studies of variant-variant and variant-plasticity interaction within aggregates. For example, the recursive method of Sittner and Novak $[21,22]$ provides a modeling-experiment approach with which to supplant the martensite hardening matrix $\left(h_{t u}\right)$ in the present FE simulations. However, the present work also requires information about phase transformation-plasticity coupling at the subaggregate (discrete variant) scale. Currently, quantitative information about such coupling is lacking. Inelastic deformation processes in martensite, such as detwinning and reorientation, can be addressed as described by Pan et al. [26]. In principle, martensite plasticity can also be incorporated, but detailed experimental evidence of operative slip systems and critical stresses for activation is lacking. Given the recent observations of complex dislocation structures induced by transformation $[25,29,30]$, it is remarkable that an aggregate-based, grain-scale model is so successful.

\section{Acknowledgements}

D.G. and R.N. acknowledge support from the NASA Fundamental Aeronautics Program (Dr. Dale Hopkins, API). P.M.A. and S.M. acknowledge Dr. MyoungGyu Lee (assistance with texture analysis), Dr. Michael Mills (discussions about austenite plasticity), Dr. Nick Hatcher (elastic constants), the NASA Fundamental Aeronautics Program, Supersonics Project (Grant No. NNX08AB49A), the Department of Energy (Grant No. DE-SC0001258) and the Ohio Supercomputer Center (Grant No. PAS676). R.V. and O.B. acknowledge experimental assistance from Sven Vogel at Los Alamos National Laboratory, the NASA Fundamental Aeronautics Program, Supersonics Project (Grant No. NNX08AB51A) and the Florida Center for Advanced Aeropropulsion.

\section{References}

[1] Wu XD, Sun GJ, Wu JS. Mater Lett 2003;57:1334.

[2] Padula SA, Qiu S, Gaydosh DJ, Noebe RD, Bigelow GS, Garg A, Vaidyanathan R. Metall Mater Trans A 2011; accepted for publication.

[3] Padula SA, Gaydosh DJ, Noebe RD, Bigelow GS, Garg A, Lagoudas D, et al. In: Dapino MJ, Ounaies Z, editors, Behavior and mechanics of multifunctional and composite materials, vol. 6929. Bellingham: Spie-Int Soc Optical Engineering; 2008. p. 92912.

[4] Grossman CH, Frenzel J, Sampath V, Depka T, Eggeler G. Metall Mater Trans A 2009;40A:2530.

[5] Bekker A, Brinson LC. J Mech Phys Solids 1997;45:949.

[6] Panico M, Brinson LC. J Mech Phys Solids 2007;55:2491.

[7] Boyd JG, Lagoudas DC. Int J Plasticity 1996;12:805.

[8] Hartl DJ, Chatzigeorgiou G, Lagoudas DC. Int J Plasticity 2010;10:1485.

[9] Lagoudas DC, Entchev PB. Mech Mater 2004;36:865. 
[10] Lagoudas DC, Entchev PB, Popov P, Patoor E, Brinson LC, Gao XJ. Mech Mater 2006;38:430.

[11] Patoor E, Lagoudas DC, Entchev PB, Brinson LC, Gao XJ. Mech Mater 2006:38:391.

[12] Anand L, Gurtin ME. J Mech Phys Solids 2003;51:1015.

[13] Thamburaja P, Anand L. Int J Plasticity 2002;18:1607.

[14] Siredey N, Patoor E, Berveiller M, Eberhardt A. Int J Solids Struct 1999;36:4289.

[15] Gall K, Sehitoglu H. Int J Plasticity 1999;15:69.

[16] Lim TJ, McDowell DL. J Mech Phys Solids 2002;50:651.

[17] Wang XM, Xu BX, Yue ZF. Int J Plasticity 2008;24:1307.

[18] Kouznetsova VG, Geers MGD. Mech Mater 2008;40:641.

[19] Idesman AV, Cho JY, Levitas VI. Appl Phys Lett 2008:93.

[20] Hackl K, Heinen R, Schmahl W, Hasan H. Mater Sci Eng A 2007;347:481-2.

[21] Novák V, Sittner P. Mater Sci Eng A 2004;378:490.

[22] Sittner P, Novák V. Scripta Mater 2004;51:321.

[23] Patoor E, Eberhardt A, Berveiller M. J Phys IV 1996;6:277.

[24] Gao XJ, Huang MS, Brinson LC. Int J Plasticity 2000;16:1345.

[25] Niclaeys C, Ben Zineb T, Arbab-Chirani S, Patoor E. Int J Plasticity 2002;18:1619.

[26] Pan H, Thamburaja P, Chau FS. Int J Plasticity 2007;23:711.

[27] Norfleet DM, Sarosi PM, Manchiraju S, Wagner MFX, Uchic MD, Anderson PM, et al. Acta Mater 2009;57:3549.

[28] Delville R, Malard B, Pilch J, Sittner P, Schryvers D. Int J Plasticity 2011;27:282.

[29] Simon T, Kroger A, Somsen C, Dlouhy A, Eggeler G. Acta Mater 2010;58:1850.

[30] Hamilton RF, Sehitoglu H, Chumlyakov Y, Maier HJ. Acta Mater 2004;52:3383.

[31] Jones NG, Dye D. Intermetallics, doi:10.1016/j.intermet.2011.03.032.

[32] Manchiraju S, Anderson PM. Int J Plasticity 2010;10:1508.

[33] Peirce D, Asaro RJ, Needleman A. Acta Metall 1982;30:1087.

[34] Hatcher N, Kontsevoi OY, Freeman AJ. Phys Rev B 2009:80.

[35] Heinen R, Hackl K, Windl W, Wagner MFX. Acta Mater 2009;57:3856.
[36] Wenk HR, Lutterotti L, Vogel S. Nucl Instrum Meth Phys Res Sec A 2003;515:575.

[37] Qiu S, Krishnan VB, Padula SA, Noebe RD, Brown DW, Clausen B, et al. Appl Phys Lett 2009:95.

[38] Jiang F, Liu Y, Yang H, Li L, Zheng Y. Acta Mater 2009;57:4773.

[39] Bigalow GS, Garg A, Padula SA, Gaydosh DJ, Noebe RD. Scripta Mater 2011;64:725.

[40] Gall K, Maier HJ. Acta Mater 2002;50:4643.

[41] Frick CP, Ortega AM, Tyber J, Maksound AEM, Maier HJ, Liu Y, et al. Mater Sci Eng A 2005;405:34.

[42] Olgricht J, Yawny A, Condo AM, Lovey FC, Eggeler G. Mater Sci Eng A 2008;142:481-2.

[43] Miyazaki S, Ohmi Y, Otsuka K, Suzuki Y. J Phys 1982; 43(Suppl 120):C4-255.

[44] Otsuka K, Ren Z. Prog Mater Sci 2005;50:511.

[45] ABAQUS reference manuals, Providence, RI; 2008.

[46] Kallend JKU, Rollett S, Wenk H. The preferred orientation package from Los Alamos, Los Alamos National Laboratory. Warrendale, PA: TMS; 1989.

[47] Bhattacharya K. Microstructure of martensite. Oxford: Oxford University Press; 2003.

[48] Hane KF, Shield TW. Acta Mater 1999;47:2603.

[49] Lee EH. J Appl Mech 1969;36:1.

[50] Turteltaub S, Suiker ASJ. Int J Solids Struct 2006;43:4509.

[51] Wagner MFX, Windl W. Acta Mater 2008;56:6232.

[52] Chumlyakov YI, Surikova NS, Korotayev AD. Fizika Metallov I Metallovedenie 1996;82:148.

[53] McKelvey AL, Ritchie RO. Philos Mag A 2000;80:1759.

[54] Zhang HY, Anderson PM, Daehn GS. Metall Mater Trans A 1994;25:415.

[55] Rajagopalan S, Little AL, Bourke MAM, Vaidyanathan R. Appl Phys Lett 2005;86:3.

[56] Qiu S, Padula SA, Noebe RD, Gaydosh DJ, Vaidyanathan R. Acta Mater 2011;59:5055-66.

[57] Gao XJ, Brown DW, Brinson LC. Smart Struct Integ Sys 2005;5764:715. 